\title{
Análise de conteúdo, usabilidade e navegabilidade de sítios eletrônicos da internet de prestadoras de serviços de abastecimento de água e esgotamento sanitário do Brasil
}

\author{
Analysis of content, usability and navigability of internet websites of \\ watersupplys and sanitation service providers in Brazil
}

\section{Hygor Aristides Victor Rossoni | Izabel Cristina Chiodi de Freitas | Sonaly Cristina Rezende Borges de Lima | Fernanda Fonseca Pessoa Rossoni}

Data de entrada: 10/12/2012 | Data de aprovação: 26/08/2013

DOI: http://dx.doi.org/10.4322/dae.2014.118

Resumo

Com o propósito de analisar o conteúdo, a usabilidade e a navegabilidade de sítios eletrônicos de Prestadoras de Serviços de Abastecimento de Água e Esgotamento Sanitário, foram selecionadas para estudo as páginas eletrônicas de duas autarquias municipais; uma companhia pública estadual e duas companhias públicas - uma de capital misto e, outra, aberto. Para tanto, foi utilizada a metodologia de pesquisa qualitativa: análise de conteúdo temático-categorial. Foi constatado que as companhias de saneamento priorizam conteúdo de informações de interesse de investidores, de promoção institucional e da gestão de qualidade dos serviços e produtos. Além disso, elas possuem um comportamento mais próximo de empresas privadas, por tratarem os usuários dos serviços como clientes. As autarquias municipais, por sua vez, abordam prioritariamente informações do interesse dos usuários voltadas para a gestão ambiental e a responsabilidade social, o que pode representar maior assimilação por parte do agente público de que o saneamento é um direito essencial da população e um dever do Estado. Uma conclusão plausível é que a abordagem e o acesso às informações não são apresentados de forma adequada, principalmente em relação à qualidade da água. Além disso, os sítios analisados possuem baixa usabilidade e navegabilidade, o que dificulta ainda mais sua apropriação pelos usuários.

Palavras-chave: Análise de Conteúdo; Abastecimento de Água e Esgotamento Sanitário; Navegabilidade; Usabilidade; Sítios Eletrônicos.

\begin{abstract}
In order to analyze the content, usability and navigability of Water Supplys and Sanitation Service Provider websites, the following webpages were selected for study: two municipal autarchies; one public, state-administered company; and, two public companies of mixed funding. Qualitative research methodology was used for both, including analysis of thematic-categorical content. It was observed that companies prioritize the informational content of interest to investors, institutional promotion, and the quality management of services and products. In addition to this, their behavior is closer to that of private businesses, treating service users like clients. Municipal autarchies, on the other hand, prioritize information of interest to users and focused on environmental management and social responsibility, which may represent a greater understanding by the public agent that environmental sanitation is an essential right of the people and an obligation of the State. A first conclusion is that the approach and access to information are not presented in an appropriate way, mainly in regard to water quality. In addition to this, the websites analyzed have low usability and navigability, which makes their utilization even more difficult for the users.
\end{abstract}

Key-words: Content Analysis; Water Supplys and Sanitation; Navigability; Usability; Websites.

${ }^{*}$ Curriculum dos autores - ver página 30 


\section{Introdução}

Nos últimos anos, houve certo avanço na cobertura dos serviços de saneamento no Brasil, conforme aponta a Pesquisa Nacional de Saneamento Básico (PNSB) ${ }^{1}$ (IBGE, 2010). Entretanto, cerca de 12 milhões de domicílios no País ainda não têm acesso à rede de abastecimento de água, dados que são indicativos da cobertura e não revelam problemas de perdas de água e de intermitência no abastecimento, além de nada informar sobre a potabilidade da água. É possível verificar, também, que o atendimento à população com serviços de saneamento apresenta grandes desigualdades regionais; inclusive, os déficits são tão maiores quanto mais ao norte estão localizados os municípios (IBGE, 2010).

No Brasil, são adotados diferentes modelos institucionais para os serviços de saneamento (PEIXOTO, 2010 e HELLER, 2012): i) serviços vinculados à Administração Direta Municipal em que a Prefeitura Municipal é a responsável pelas atividades de planejamento, projeto, operação e administração; ii) Administração Indireta Municipal - administração municipal concede, por meio de lei específica, ou permite, por licitação pública, a gestão e/ou operação dos serviços de saneamento por empresas públicas (Ex: autarquias ou empresas companhias públicas municipais), podendo também ser um modelo empresarial de gestão e operação dos serviços de saneamento por meio de concessões obtidas junto aos titulares dos serviços (municípios); iii) Companhias Estaduais - consistem em empresas públicas e/ou de economia mista que obedecem a um sistema centralizador administrativo e financeiro, sendo que a operação dos serviços e manutenção são realizadas por meio de escritórios regionais; iv) Empresas Privadas - consistem em acordo firmado entre a administração pública e entes privados, os quais estabelecem vínculo jurídico entre si, visando à implantação ou gestão, no todo ou em parte dos serviços; v) Consórcios - forma de auto-organização, com baixa participação dos governos estaduais e federal, regulada pela Lei 11.107/05 e prevista, também, na Lei 11.445/07, que oficializa a oportunidade de gestão associada entre municípios, a qual pode incluir entes estaduais e federais. Consórcios Intermunicipais de Saneamento devem conter a ratificação, por lei, de Protocolo de Intenções, seguida da celebração de convênio específico entre o Município consorciado e o Consórcio, em que devem ficar bem definidas as competências atribuídas ao consórcio.

Apesar dos avanços no que tange à cobertura de serviços de saneamento a partir dos anos 1970, pode-se atribuir o aumento das desigualdades socioeconômicas e regionais no acesso a estes serviços à Política Nacional de Saneamento Básico, iniciada durante a ditadura militar e orientada pelos instrumentos do Plano Nacional de Saneamento Básico (PLANASA). O referido Plano, em detrimento dos demais serviços, priorizou o abastecimento de água e, em menor medida, o esgotamento sanitário, e direcionou os investimentos para regiões de economia mais dinâmica (Sul e Sudeste do Brasil), nos municípios mais desenvolvidos que fossem capazes de restituí-los. Ademais, o PLANASA condicionou o repasse de recursos aos municípios à atuação das Companhias Estaduais de Saneamento Básico (CESB) nos respectivos serviços. Assim, uma grande parcela dos municípios foi alijada dos benefícios do plano, entre eles, alguns com sistemas bastante eficientes, operados pelos próprios municípios por meio de autarquias. Nos anos 1980, período de recessão econômica no País, antes mesmo das metas iniciais do PLANASA serem alcançadas, houve contingenciamento dos recursos para o setor de saneamento, resultando em ampliação da segregação regional e de classes, fato que contribuiu ainda mais para a manutenção do quadro deficitário nas periferias urbanas e áreas rurais (REZENDE e HELLER, 2008).

A nova Política Nacional de Saneamento no Brasil (definida pela Lei $n^{\circ} 11.445 / 07$ ) inovou ao prover a sociedade de uma legislação que regulasse o assunto, promover a transparência e viabilizar o controle social, princípios que corroboram as definições e procedimentos sobre o controle de qualidade da água em sistemas de abastecimento, bem como a definição de mecanismos e instrumentos para divulgação de informação ao consumidor sobre a qualidade da água

1 Consistem em resultados da pesquisa realizada pelo IBGE sobre a oferta e a qualidade dos serviços de saneamento ambiental no Brasil, realizada periodicamente, com base em consultas aos titulares - autoridades municipais - e empresas contratadas para prestar serviços de abastecimento de água, esgotamento sanitário, drenagem urbana e coleta de resíduos sólidos, em todos os municípios brasileiros. 
para consumo humano (BRASIL, 2005).

Em relação à instrumentalização e organização de pesquisas de caracterização sanitária dos domicílios brasileiros, vale destacar órgãos oficiais como o Instituto Brasileiro de Geografia e Estatística (IBGE) e o Ministério das Cidades, possibilitam, por meio de informações obtidas a partir de surveys, criar importantes indicadores para visão macro, mas não refletem, por exemplo, o grau de satisfação dos usuários e os investimentos em ações que garantam eficácia e sustentabilidade institucional (RUBINGER, 2008). Cabe ressaltar que estes dados reportam apenas a cobertura, no entanto, deixam de lado a análise sobre o nível de qualidade e a forma de acesso $^{2}$ aos serviços de saneamento pela população.

Assim, a divulgação da qualidade dos serviços prestados se estabelece de forma institucional e permanente e, naturalmente, em virtude do crescente número de usuários no mundo todo e do grande impacto que a internet exerce sobre a sociedade, este meio de comunicação tem revelado ser poderosa ferramenta para a divulgação de produtos, serviços, promoções, imagem da marca e ferramentas de relacionamento com o cliente (LUK et al., 2002; CHO \& KHANG, 2006).

Em compilação de diferentes autores, Heller e Castro (2007, p. 286) extraem o seguinte conceito para política pública: “... processo que envolve decisões por parte de corpos e autoridades governamentais e ações, realizadas por um ator ou um conjunto de atores, e é composto por metas e os meios para alcançá-las". Portanto, o saneamento está contido na esfera da política pública, área de atuação do Estado que demanda formulação, avaliação, organização institucional e participação cidadã (HELLER e CASTRO, 2007).

Nesse contexto, este artigo tem por objetivos analisar e avaliar o conteúdo de sítios eletrônicos da internet de prestadoras de serviços de abastecimento de água e esgotamento sanitário no Brasil, com foco na usabilidade e navegabilidade. É importante ressaltar o valor da contribuição de trabalhos centrados na verificação do direito de acesso à informação, como vetor de estímulo à participação e ao controle social dos usuários junto às prestadoras de serviços.

\section{Marcos Legais e a Provisão dos Serviços de Sa- neamento}

A Organização das Nações Unidas (ONU), em resolução histórica - A/RES/64/292 de 28 de julho de 2010 - declarou o acesso à água potável e ao esgotamento sanitário um direito humano (ONU, 2012). Esse novo cenário, inquestionavelmente, requalifica os papéis dos agentes públicos e sociais que atuam no saneamento brasileiro. $\mathrm{O}$ Brasil, em termos de serviços de abastecimento de água, tem atendido padrões internacionais, conforme estudo do Instituto de Pesquisa Econômica e Aplicada (IPEA, 2004). No país, a meta para saneamento dos Objetivos do Milênio com relação ao abastecimento de água é de $84,9 \%$ da população atendida até 2015 , já tendo sido ultrapassado o previsto.

Assim, a adoção de políticas públicas voltadas para o atendimento aos princípios da economicidade e eficiência, prevendo a aplicação de recursos de forma responsável é amplamente desejável, pois deverá gerar o máximo benefício à população, respeitando a realidade regional e local.

Tal análise alinha-se às diretrizes para o saneamento, delineadas na Lei Federal 11.445/2007 (BRASIL, 2007), no que diz respeito aos seus princípios fundamentais que envolvem a transparência e o controle social.

Por outro lado, o Decreto Presidencial 5.440/2005 estabelece definições e procedimentos sobre o controle de qualidade da água de sistemas de abastecimento público e institui mecanismos e instrumentos para divulgação de tais informações ao consumidor (BRASIL, 2005). O princípio norteador é a garantia da informação, a qual implica em transparência nas relações de consumo conforme o Código de Defesa do Consumidor, sendo que o decreto citado regulamenta, especificamente, a informação relativa à qualidade da água para consumo e, sobretudo, busca aproximar usuários, setor de saúde e responsáveis por sistemas e soluções alternativas (BRASIL, 2006).

2 É importante ressaltar que, para a caracterização do atendimento e do déficit de acesso ao saneamento no Brasil, durante a elaboração do Plano Nacional de Saneamento Básico (Plansab), buscou-se uma definição para a análise da situação tendo em conta a infraestrutura implantada, os aspectos socioeconômicos e culturais e a qualidade dos serviços oferecidos ou solução empregada. Neste sentido, os diferentes componentes do saneamento podem ser classificados em relação ao atendimento em: adequado, precário e sem atendimento. Para mais informações, ver a proposta Plansab (SNSA, 2011, p.19). 
Importância do Acesso à Informações e da Análise de Conteúdo de Sítios Eletrônicos

Segundo pesquisa do Instituto Brasileiro de Opinião Pública e Estatística (IBOPE, 2012), o Brasil possuía, em 2011, 79,9 milhões de internautas, sendo considerado o $5^{\circ}$ país mais conectado. Dentre o total de internautas brasileiros, $87 \%$ acessavam a internet pelo menos uma vez por semana e a mesma proporção utilizava a rede para pesquisar produtos e serviços (CETIC, 2012).

Com tantas pessoas acessando a internet, atualmente ela é a segunda maior mídia de massa nacional e, portanto, merece investimentos maiores (OHIRA, et al., 2003). Nesse sentido, as páginas passaram a agregar informações úteis e organizadas, cujo valor passou a ser determinante para que os usuários o visitem novamente, aliado à preocupação com a navegação na rede, o que resulta no desenvolvimento e na aplicação de diversos mecanismos/ferramentas de busca.

Dessa forma, a internet atende ao que Shimp (2009) denominou "objetivos específicos da mídia”: i) alcance: número maior de pessoas; ii) frequência: período em que são expostas as informações; iii) peso: quantidade de informações a ser veiculada no período; e iv) custo: meio de comunicação mais barato que os tradicionais.

Como afirmou Vilella (2003), a internet é uma mídia que está em permanente construção e reconstrução, por isto, a avaliação apresenta-se como uma prática muito importante. Neste contexto, destacam-se a usabilidade e a navegabilidade como critérios de avaliação. A usabilidade é a extensão em que um produto pode ser usado por determinados usuários para alcançar objetivos específicos com eficácia, eficiência e satisfação em um contexto de uso. Por sua vez, a navegabilidade é a forma de organização da informação para que o usuário navegue intuitivamente e saiba onde está e de onde veio, bem como quais são as suas possibilidades futuras de acesso (VILELLA, 2003).

Há diversas formas para que informações sobre a qualidade da água cheguem até o consumidor: correspondência individual, contas de água, cartazes, folhetos, páginas eletrônicas da internet, divulgação em veículos de comunicação de massa (jornal, rádio e televisão). Nesse sentido, as informações vinculadas a sítios eletrônicos possuem excelente potencial difusor - devido ao seu alto grau de acessibilidade e por facilitar o fornecimento de informações ao consumidor com maior riqueza de detalhes.

Por este motivo, os conteúdos virtuais de organizações devem ser avaliados periodicamente. Um dos instrumentos para tal é a análise de conteúdo, a qual consiste em um conjunto de técnicas ou procedimentos objetivos e sistemáticos de descrição do conteúdo das mensagens, visando obter indicadores (quantitativos ou não) que permitam a inferência de conhecimentos relativos às condições de produção/recepção destas mensagens (BARDIN, 2011; OLIVEIRA, 2008).

\section{Material e métodos}

Para o desenvolvimento desta pesquisa foi utilizado o método da análise de conteúdo temático-categorial, que, conforme Bardin (2011) consiste em descobrir os núcleos de sentido que compõem uma comunicação cuja presença ou frequência tenham algum significado para o objetivo analítico visado.

Após a formulação dos objetivos, a análise foi dividida em três etapas, conforme preconizado por Oliveira, 2008: i) pré-análise: definição do corpus por meio da leitura flutuante; formulação das categorias; ii) exploração do material: agregação dos dados brutos em características pertinentes ao conteúdo expresso nos sítios eletrônicos; e iii) tratamento dos resultados, inferência e interpretação: quantificação simples (frequência) e análise qualitativa comparativa dos dados.

Para a definição do corpus, os critérios foram estabelecidos com base nas páginas principais (menus principais) e nas de segundo nível dos sítios eletrônicos (links e ícones internos): isto porque, ao mesmo tempo em que analisa o conteúdo da primeira página, o internauta avalia, ainda que inconscientemente, a aparência do sítio eletrônico (FERRARI; 2008; CHO e KHANG; 2006; LUK et. al., 2002). Neste contexto, a análise de conteúdo dessas páginas possui relevância no que diz respeito à verificação da abordagem das informações pelas prestadoras de um serviço que é essencial para a população.

Também foram realizadas análises específicas nos conteúdos dos seguintes elementos dos sítios eletrônicos: i) Missão e Visão Institucional; ii) cumprimento do Decreto 5440/2005 - relativo à obrigatoriedade de divulgação de informações sobre a qualidade da água e os ícones relativos a esse assunto; e iii) banners referentes a Notícias 


\begin{tabular}{l|l|l}
$\begin{array}{l}\text { Notação de } \\
\text { Referência }\end{array}$ & \multicolumn{2}{|c}{ Descrição } \\
\hline CPCA & $\begin{array}{l}\text { Companhia pública de capital aberto, criada há mais de } 35 \text { anos. Localiza-se na região Sudeste e é responsá- } \\
\text { vel pelo abastecimento de água em cerca 70\% dos municípios da federação a qual representa. }\end{array}$ \\
\hline CESB & $\begin{array}{l}\text { Companhia estadual de saneamento localizada na região Norte e fundada há } 40 \text { anos. Presente na sede de } 15 \\
\text { municípios e em } 62 \text { localidades. }\end{array}$ \\
\hline EPCM & $\begin{array}{l}\text { Empresa pública de capital misto, criada em } 1970 \text { e localizada na região Sul. Presente em 68\% dos municí- } \\
\text { pios do estado. }\end{array}$ \\
\hline SAAE/01 & Atua em um município com aproximadamente 45 mil habitantes. & $\begin{array}{l}\text { Autarquias municipais autônomas, } \\
\text { criadas há mais de 30 anos e localizadas } \\
\text { na região Sudeste. Originalmente foram } \\
\text { administradas e conveniadas com a Fun- } \\
\text { dação Nacional de Saúde (FUNASA). }\end{array}$ \\
\hline SAAE/02 & Atua em um município com aproximadamente 30 mil habitantes. \\
\hline
\end{tabular}

Tabela 1 - Notação de referência e descrição das organizações prestadoras dos serviços de abastecimento de água e esgotamento sanitário analisadas no presente estudo

e Projetos.

Apesar de o presente trabalho representar um conjunto real de sítios eletrônicos de prestadoras de serviços de saneamento do Brasil, houve a opção por resguardar sua identificação, assim, da mesma forma, durante a apresentação dos resultados, foram omitidas as denominações das empresas. Para designá-las, utilizaram-se notações de referência. É importante salientar que o fato de ter sido assumida a premissa de profundidade da metodologia qualitativa não foi ensejado, por pretensão, que este trabalho seja representativo de realidade mais abrangente, mas, sim, um estudo que busque, com intensidade, inferências dos pesquisadores sobre o fenômeno estudado.

De toda forma, deve ser entendido que a discussão a partir da seleção amostral em questão, traz à tona aspectos que refletem uma realidade mais geral e menos particular. Como destaca Flick (2011), este tipo de estudo permite identificar problemas, fazer interações específicas, entender padrões e detalhes, obter juízos de valor e realizar interpretações, caracterizar a riqueza de um tema e explicar fenômenos de abrangência limitada.

Na Tabela 1, estão descritas as notações de referências adotadas, bem como a descrição sumarizada das características de localização, porte e modelos de gestão das cinco prestadoras de serviços de saneamento analisadas no presente estudo.

A coleta de informações e a análise do conteúdo foram realizadas no período de 02 de novembro a 14 de dezembro de 2011. Para tal, foram utilizados os seguintes instrumentos:

a) Agrupamento (categorias de conteúdo) e

\begin{tabular}{l|l|}
\multicolumn{1}{|c|}{ Categorias de conteúdos } & \multicolumn{1}{c|}{ Descrição } \\
\hline Política Institucional & $\begin{array}{l}\text { Relacionada ao planejamento estratégico e com a posição assumida e defendida } \\
\text { pela empresa. Destacam-se a Visão e a Missão Institucional (DIAS, 2009). }\end{array}$ \\
\hline $\begin{array}{l}\text { Gestão da Qualidade do Produto e } \\
\text { Serviço }\end{array}$ & $\begin{array}{l}\text { Estratégias de administração orientadas a criar consciência da qualidade em todos } \\
\text { os processos organizacionais, tanto na prestação do serviço, quanto do produto } \\
\text { (FERRARI, 2008). }\end{array}$ \\
\hline $\begin{array}{l}\text { Gestão Ambiental e Responsabilidade } \\
\text { Social }\end{array}$ & $\begin{array}{l}\text { Também denominada gestão socioambiental, possui o intuito de sensibilizar os em- } \\
\text { preendedores para que possam atuar segundo o seguinte pressuposto: “a empresa } \\
\text { deve ser socialmente justa e ambientalmente responsável” (SEIFFERT, 2008). }\end{array}$ \\
\hline $\begin{array}{l}\text { Informações aos Usuários, } \\
\text { Fornecedores e Investidores }\end{array}$ & $\begin{array}{l}\text { Constituem ferramentas fundamentais para a melhoria da interface e comunicação } \\
\text { entre a empresa e usuários/ fornecedores/ investidores. }\end{array}$ \\
\hline Identidade Visual & $\begin{array}{l}\text { Conjunto de elementos gráficos que representam visualmente e de forma sistematizada, } \\
\text { um nome, ideia, produto, empresa, instituição ou serviço (FERRARI, 2008). }\end{array}$ \\
\hline
\end{tabular}

Tabela 2 - Descrição dos critérios para a análise de conteúdo temático-categorial dos links do menu principal e ícones internos da página inicial dos sítios eletrônicos de estudo 
Critérios Avaliativos

\begin{tabular}{l|l|}
\hline Usabilidade & $\begin{array}{l}\text { Capacita o usuário a realizar facilmente tarefas associadas ao uso do sítio. Entre os critérios de ava- } \\
\text { liação, destacam-se: planejamento visual/gráfico; interface com o usuário; facilidade de navegação; } \\
\text { habilidade de executar tarefas com um menor número de cliques e integração e execução de tarefas } \\
\text { de forma facilitada (OHIRA et al., 2003; VILELLA, 2003) }\end{array}$ \\
\hline $\begin{array}{l}\text { Navegabilidade } \\
\text { (Cyberworthiness) }\end{array}$ & $\begin{array}{l}\text { Propriedade ou capacidade de navegação que possui a interface de um portal na internet, ou o próprio } \\
\text { software navegador, de facilitar ao usuário chegar ao seu destino da maneira mais segura e eficiente } \\
\text { possivel. Os elementos de navegação oferecem a visão panorâmica de todo o conteúdo, destacando-se } \\
\text { as tabelas de conteúdo, os índices e, sobretudo, os mapas de site (FERRARI, 2008). }\end{array}$ \\
\hline
\end{tabular}

Tabela 3 - Critérios avaliativos de usabilidade e navegabilidade

\begin{tabular}{l|l|c}
\multicolumn{1}{c}{ Critérios } & \multicolumn{1}{c}{ Critérios de Ponderação } & Conceitos \\
\hline Bom (B) & Apresenta todos os requisitos necessários e esperados para os parâmetros analisados. & 3 \\
\hline Satisfatório (S) & Proporciona uma abordagem regular e aceitável dos parâmetros analisados. & 2 \\
\hline Parcial (P) & Atende de forma parcial, mas deixa a desejar na plenitude dos requisitos estudados. & 1 \\
\hline Insuficiente (I) & Aborda os critérios estudados de forma escassa, incompleta e deficiente. & 0 \\
\hline
\end{tabular}

Fonte: critérios estabelecidos pelos autores do estudo.

Tabela 4 - Conceitos e pesos utilizados no ranking para classificação dos sítios eletrônicos em termos de usabilidade e navegabilidade.

exploração do material: visando à descrição da abordagem de conteúdo dos links e ícones nas páginas principais e de segundo nível predominante dos sítios, buscando responder quais são os focos de abordagem das informações (Tabela 2). Ao final, os links dos menus principais e ícones internos foram agrupados, a fim de contabilizar a frequência de ocorrência $(F)$ e percentual (P) de cada uma das cinco categorias definidas e analisadas.

b) Inferência e avaliação geral: construção analítica baseada no levantamento da qualidade geral (aspectos positivos e negativos) do sítio eletrônico, baseados exclusivamente na usabilidade e navegabilidade (Tabela 3). A análise final dos dados foi efetuada por meio de ponderações qualitativas e a posterior dotação de pesos para o estabelecimento de ranking comparativo dos sítios analisados em função dos critérios referentes à análise de conteúdo, usabilidade e navegabilidade.

Na Tabela 4, encontram-se os atributos e pesos relativos à análise final. Ressalta-se que esta avaliação limita-se exclusivamente à percepção de uso e navegação nos sítios eletrônicos correspondentes ao período da análise.

\section{Resultados e discussão}

Os resultados referentes à análise de conteúdo temático-categorial das páginas iniciais dos sítios eletrônicos deste estudo estão resumidos na Tabela 5. No que respeita a identidade visual, a principal intenção é que sejam reforçados os conceitos de organização, solidez, coerência e afirmação da personalidade da marca. Também é percebido que, na conformação do simbolismo, todas as prestadoras utilizaram as cores azul, branca e verde, em alusão ao elemento água, com a pretensão de passar a impressão de prestadora "limpa" e dinâmica, que visa à proteção dos recursos naturais renováveis.

Quanto ao slogan das prestadoras dos serviços de saneamento, as autarquias municipais focalizaram o produto (SAAE/01: "Qualidade em cada gota" e SAAE/02: "Cuidando da água que alimenta a vida"), enquanto a empresa pública de capital misto focalizou a gestão e promoção institucional (EPCM: "Inovação; Agilidade e Transparência”). No entanto, com base nas considerações de Shimp (2009), foi constatado que as frases dos slogans das autarquias municipais são genéricas e buscam promover diretamente os atributos ou benefícios do serviço ou do produto sem declaração de superioridade. Porém, vale destacar que, 


\begin{tabular}{|c|c|c|c|c|c|c|}
\hline \multirow{3}{*}{$\begin{array}{l}\text { Categorias } \\
\text { tematicas }\end{array}$} & \multirow{3}{*}{$\begin{array}{l}\text { Subcatego- } \\
\text { rias }\end{array}$} & \multicolumn{5}{|c|}{ Prestadoras de Serviço de Saneamento } \\
\hline & & \multicolumn{2}{|c|}{ Autarquias Municipais } & \multirow{2}{*}{\begin{tabular}{|l|}
$\begin{array}{c}\text { Companhia } \\
\text { Estadual }\end{array}$ \\
CESB \\
\end{tabular}} & \multicolumn{2}{|c|}{$\begin{array}{c}\text { Empresa/Companhia Pública (aberta ou } \\
\text { mista) }\end{array}$} \\
\hline & & SAAE/01 & SAAE/02 & & EPCM & CPCA \\
\hline \multirow{2}{*}{$\begin{array}{l}\text { Identidade } \\
\text { Visual }\end{array}$} & Slogan & $\begin{array}{l}\text { Qualidade em } \\
\text { cada gota }\end{array}$ & $\begin{array}{l}\text { Cuidando da } \\
\text { água que ali- } \\
\text { menta a vida }\end{array}$ & ND & $\begin{array}{l}\text { Inovação; Agilidade } \\
\text { e Transparência }\end{array}$ & ND \\
\hline & \begin{tabular}{|l|}
$\begin{array}{l}\text { Cor do } \\
\text { sítio }\end{array}$ \\
\end{tabular} & Azul claro & $\begin{array}{l}\text { Branco e azul } \\
\text { celeste }\end{array}$ & Branco e azul & Branco e verde & Branco \\
\hline \multirow{2}{*}{$\begin{array}{l}\text { Promoção } \\
\text { e Política } \\
\text { Institucio- } \\
\text { nal }\end{array}$} & $\begin{array}{l}\text { Menu } \\
\text { principal }\end{array}$ & $\begin{array}{l}\text { Responsabilidade } \\
\text { e Qualidade } \\
F=1 ; P=9,1 \%\end{array}$ & ND & $\begin{array}{l}\text { A Empresa; } \\
\text { Administração; } \\
\text { Missão e Visão; } \\
\text { Organograma } \\
F=4 ; P=25 \%\end{array}$ & $\begin{array}{l}\text { Companhia; Galeria } \\
\text { EPCM } \\
\text { F = } 2 ; P=11,1 \%\end{array}$ & $\begin{array}{l}\text { A Empresa; Logo- } \\
\text { marca } \\
F=2 ; P=18,2 \%\end{array}$ \\
\hline & $\begin{array}{l}\text { Links e } \\
\text { ícones } \\
\text { internos }\end{array}$ & ND & ND & ND & $\begin{array}{l}\text { Campanha de Va- } \\
\text { lorização da EPCM; } \\
\text { Prêmio EPCM de } \\
\text { Ecologia e Prêmio } \\
\text { EPCM de Jornalismo } \\
\text { F=3; P = 42,8 \% }\end{array}$ & ND \\
\hline \multirow[t]{2}{*}{$\begin{array}{l}\text { Gestão } \\
\text { Ambiental } \\
\text { e Respon- } \\
\text { sabilidade } \\
\text { Social }\end{array}$} & $\begin{array}{l}\text { Menu } \\
\text { principal }\end{array}$ & $\begin{array}{l}\text { Legislação; Edu- } \\
\text { cação Şocioam- } \\
\text { biental } \\
\mathrm{F}=2 ; \mathrm{P}=18,2 \%\end{array}$ & $\begin{array}{l}\text { Educaccão } \\
\text { Ambiental; } \\
\text { SAAE Orienta; } \\
\text { Sistema de } \\
\text { Água; Sistema } \\
\text { de Esgoto; } \\
\text { "Projeto"- } \\
\text { Água e Vida } \\
\text { F=5; P = 45,4\% }\end{array}$ & $\begin{array}{l}\text { ETE; ETA } \\
F=2 ; P=12,5 \%\end{array}$ & $\begin{array}{l}\text { Recursos Hídricos } \\
\text { e Meio Ambiente; } \\
\text { Saúde; Qualidade da } \\
\text { Agua; Responsabili- } \\
\text { dade Social; } \\
\mathrm{F}=4 ; \mathrm{P}=22,2 \%\end{array}$ & $\begin{array}{l}\text { Reduza sua Conta } \\
\mathrm{F}=1 ; \mathrm{P}=9,1 \%\end{array}$ \\
\hline & $\begin{array}{l}\text { Links e } \\
\text { icones } \\
\text { internos }\end{array}$ & $\begin{array}{l}\text { Enquete } \\
F=1 ; P=12,5 \%\end{array}$ & $\begin{array}{l}\text { Novidade } \\
\text { (Educaçãão } \\
\text { Ambiental) } \\
\mathrm{F}=1 ; \mathrm{P}=20 \% \\
\end{array}$ & $\begin{array}{l}\text { Dicas } \\
F=1 ; P=33,3 \%\end{array}$ & $\begin{array}{l}\text { Relatório Anual } \\
F=1 ; P=14,3 \%\end{array}$ & $\begin{array}{l}\text { Despoluição; Lagoa } \\
\text { Limpa } \\
\mathrm{F}=2 ; \mathrm{P}=18,2 \%\end{array}$ \\
\hline \multirow{2}{*}{$\begin{array}{l}\text { Gestão da } \\
\text { Qualidade } \\
\text { do Produto } \\
\text { e Serviço }\end{array}$} & $\begin{array}{l}\text { Menu } \\
\text { principal }\end{array}$ & $\begin{array}{l}\text { SAAE } \\
F=1 ; P=9,1 \%\end{array}$ & $\begin{array}{l}\text { SAAE; Contas } \\
\text { Públicas } \\
\mathrm{F}=2 ; \mathrm{P}=18,2 \%\end{array}$ & $\begin{array}{l}\text { Ações } \\
F=1 ; P=6,3 \%\end{array}$ & $\begin{array}{l}\text { Serviços; Projetos } \\
\text { e Obras; Ouvidoria } \\
\text { Geral do Estado } \\
\mathrm{F}=3 ; \mathrm{P}=5,6 \% \\
\end{array}$ & $\begin{array}{l}\text { Qualidade da Água; } \\
\text { Balanços } \\
\mathrm{F}=2 ; \mathrm{P}=9,1 \%\end{array}$ \\
\hline & \begin{tabular}{|l|} 
Links e \\
icones \\
internos \\
\end{tabular} & $\begin{array}{l}\text { Ouvidoria } \\
F=1 ; P=12,5 \%\end{array}$ & $\begin{array}{l}\text { Qualidade } \\
F=1 ; P=20 \%\end{array}$ & ND & $\begin{array}{l}\text { Qualidade da Água } \\
F=1 ; P=14,3 \%\end{array}$ & ND \\
\hline \multirow{2}{*}{$\begin{array}{l}\text { Informa- } \\
\text { ções aos } \\
\text { Usuários; } \\
\text { Fornecedo- } \\
\text { res e Inves- } \\
\text { tidores }\end{array}$} & $\begin{array}{l}\text { Menu } \\
\text { principal }\end{array}$ & $\begin{array}{l}\text { Serviços; Enten- } \\
\text { da sua Conta; } \\
\text { Licitações; } \\
\text { Notícias; Dicas e } \\
\text { Dúvidas; Central } \\
\text { de Atendimento } \\
\text { F = 7; P = } 63,6 \%\end{array}$ & $\begin{array}{l}\text { "Município"; } \\
\text { Licitaçôes; Visi- } \\
\text { tas; Perguntas } \\
\text { Frequentes } \\
\text { F = 4; P = 36,4\% }\end{array}$ & $\begin{array}{l}\text { Nosso Atendimen- } \\
\text { to; Notícias; Es- } \\
\text { trutura Tarifária; } \\
\text { Emissão de } 2^{a} \text { Via; } \\
\text { Licitações; CRC; } \\
\text { Transferência; } \\
\text { Negociação de } \\
\text { Débito; Conta de } \\
\text { Água } \\
\text { F=9; } P=56,2 \%\end{array}$ & $\begin{array}{l}\text { Concurso Públi- } \\
\text { co; Loja Virtual; } \\
\text { Regulamento de } \\
\text { Serviços; Licitações; } \\
\text { Orientações ao } \\
\text { Cliente; Saiba Mais; } \\
\text { Marcos Geodésicos; } \\
\text { Investidores; Fale } \\
\text { Conosco } \\
\text { F=9; P = 61,1\% }\end{array}$ & $\begin{array}{l}\text { Licitações; Relação } \\
\text { com os Investidores; } \\
\text { Aprenda Conosco; } \\
\text { Resumo da Semana; } \\
\text { Guia do Usuário; } \\
\text { Informativo } \\
\mathrm{F}=6 ; \mathrm{P}=54,5 \%\end{array}$ \\
\hline & $\begin{array}{l}\text { Links e } \\
\text { ícones } \\
\text { internos }\end{array}$ & $\begin{array}{l}\text { Newsletter; } \\
\text { Dicas e Dúvidas; } \\
\text { Últimas Notícias; } \\
\text { Fale com o Presi- } \\
\text { dente; } 2^{\mathrm{a}} \text { Via de } \\
\text { conta } \\
\text { F = 6; P }=75 \%\end{array}$ & $\begin{array}{l}\text { Newsletter do } \\
\text { SAAE; } \\
\text { Estágio; Gale- } \\
\text { ria de Fotos } \\
\mathrm{F}=3 ; \mathrm{P}=60 \%\end{array}$ & $\begin{array}{l}\text { Fale Conosco; } \\
\text { Sua Conta } \\
F=2 ; P=66,7 \%\end{array}$ & $\begin{array}{l}\text { Pagamento da } \\
\text { Conta/Segunda Via; } \\
\text { Loja Virtual } \\
\mathrm{F}=2 ; \mathrm{P}=28,6 \%\end{array}$ & $\begin{array}{l}\text { Pregão Eletrônico; } \\
\text { Visitação Ambiental; } \\
\text { Fale com a CPCA; } \\
\text { Consulta ao Cadas- } \\
\text { tro; Guia do Usuário; } \\
\text { Agência de Atendi- } \\
\text { mento; Nada Consta; } \\
\text { Últimas Contas; } 2^{\text {a Via }} \\
\text { e contas vencidas } \\
\text { F = 9; } P=81,8 \%\end{array}$ \\
\hline \multirow{2}{*}{$\begin{array}{l}\text { Frequência } \\
\text { (F) total de } \\
\text { subcatego- } \\
\text { rias }\end{array}$} & $\begin{array}{l}\text { Menu } \\
\text { principal }\end{array}$ & 11 & 11 & 16 & 18 & 11 \\
\hline & \begin{tabular}{|l} 
Links e \\
ícones \\
internos
\end{tabular} & 8 & 5 & 3 & 7 & 11 \\
\hline \multirow[t]{2}{*}{$\begin{array}{l}\text { Inferências } \\
\text { Específicas }\end{array}$} & \begin{tabular}{|l|} 
Página \\
como \\
instrumen- \\
to para \\
cumprir \\
o decreto \\
$\mathbf{5 4 4 0 / 0 5}$ \\
\end{tabular} & $\begin{array}{l}\text { Status do abas- } \\
\text { tecimento de } \\
\text { água em tempo } \\
\text { real }\end{array}$ & NC & NC & $\begin{array}{l}\text { Relatório anual } \\
\text { de qualidade das } \\
\text { águas, 2011, mas os } \\
\text { dados são de } 2010, \\
\text { muito técnico, sem } \\
\text { análise, "carrega- } \\
\text { do" }\end{array}$ & $\begin{array}{l}\text { Relatórios mensal, } \\
\text { trimestral, semes- } \\
\text { tral e anual sobre a } \\
\text { qualidade da água, } \\
\text { também burocrático, } \\
\text { técnico }\end{array}$ \\
\hline & $\begin{array}{l}\text { Notícias/ } \\
\text { projetos }\end{array}$ & $\begin{array}{l}\text { Notícias gerais; } \\
\text { dois projetos: } \\
\text { Separaração e } \\
\text { Fiscal da água }\end{array}$ & $\begin{array}{l}\text { Informações } \\
\text { gerais sobre a } \\
\text { cidade; Educa- } \\
\text { ção ambiental }\end{array}$ & $\begin{array}{l}\text { Não consta; é } \\
\text { uma página em } \\
\text { construção, sim- } \\
\text { ples, "enxuta" }\end{array}$ & $\begin{array}{l}\text { Link específico } \\
\text { sobre responsabili- } \\
\text { dade social: Prosa- } \\
\text { near, tarifa social, } \\
\text { aprendiz etc. }\end{array}$ & $\begin{array}{l}\text { Links interagindo com } \\
\text { outras acões de go- } \\
\text { verno: PÁC, "Estado" } \\
\text { contra a dengue }\end{array}$ \\
\hline
\end{tabular}

Onde: $N D=$ Não Disponível; $P=$ Porcentagem (\%); $N C$ = Não Consta.

Tabela 5 - Quadro resumo da análise de conteúdo temático-categorial da página inicial dos sítios eletrônicos analisados. 


\begin{tabular}{|c|c|c|c|c|c|c|}
\hline \multirow{3}{*}{$\begin{array}{l}\text { Categorias } \\
\text { temáticas }\end{array}$} & \multirow{3}{*}{ Inferência } & \multicolumn{5}{|c|}{ Prestadoras de Serviço de Saneamento } \\
\hline & & \multicolumn{2}{|c|}{ Autarquias Municipais } & \multirow{2}{*}{$\begin{array}{c}\begin{array}{c}\text { Companhia Esta- } \\
\text { dual }\end{array} \\
\text { CESB } \\
\end{array}$} & \multicolumn{2}{|c|}{$\begin{array}{c}\text { Empresa/Companhia Pública (aberta ou } \\
\text { mista) }\end{array}$} \\
\hline & & SAAE/01 & SAAE/02 & & EPCM & CPCA \\
\hline \multirow[t]{3}{*}{ Missão } & $\begin{array}{l}\text { Unidade } \\
\text { de Con- } \\
\text { texto }\end{array}$ & $\begin{array}{l}\text { Contribuir para } \\
\text { melhoria de vida } \\
\text { das pessoas, pres- } \\
\text { tando serviços de } \\
\text { saneamento com } \\
\text { universalidade } \\
\text { e qualidade no } \\
\text { município }\end{array}$ & ND & $\begin{array}{l}\text { Prestar adequada- } \\
\text { mente os serviços } \\
\text { de abastecimento } \\
\text { de água e esgota- } \\
\text { mento sanitário, } \\
\text { com equilíbrio eco- } \\
\text { nômico-financeiro, } \\
\text { universalizando o } \\
\text { atendimento, con- } \\
\text { tribuindo para me- } \\
\text { lhoria da qualidade } \\
\text { de vida e da saúde } \\
\text { da população } \\
\end{array}$ & $\begin{array}{l}\text { Fornecer água } \\
\text { tratada. Coletar } \\
\text { e tratar esgotos } \\
\text { sanitários, pro- } \\
\text { movendo saúde, } \\
\text { conforto, quali- } \\
\text { dade de vida e } \\
\text { desenvolvimen- } \\
\text { to sustentável }\end{array}$ & $\begin{array}{l}\text { Prestar serviços de } \\
\text { abastecimento de } \\
\text { água e esgotamento } \\
\text { sanitário que contri- } \\
\text { buam para a melhoria } \\
\text { da qualidade de vida } \\
\text { da população e para } \\
\text { o desenvolvimento } \\
\text { socioeconômico, com } \\
\text { rentabilidade, visando } \\
\text { à satisfação da socie- } \\
\text { dade, dos clientes e } \\
\text { acionistas } \\
\end{array}$ \\
\hline & $\begin{array}{l}\text { Localiza- } \\
\text { ção no Site }\end{array}$ & $\begin{array}{l}\text { “Responsabilidade } \\
\text { e Qualidade” => } \\
\text { Perfil }\end{array}$ & ND & “Missão e Visão" & $\begin{array}{l}\text { "Companhia" } \\
=>\text { Missão }\end{array}$ & "Guia do Usuário" \\
\hline & $\begin{array}{l}\text { Unidade } \\
\text { de Regis- } \\
\text { tro }\end{array}$ & $\begin{array}{l}\text { Melhoria de vida; } \\
\text { saneamento; } \\
\text { universalidade; } \\
\text { qualidade }\end{array}$ & ND & $\begin{array}{l}\text { Abastecimento de } \\
\text { água; esgotamento } \\
\text { sanitário; equilí- } \\
\text { brio econômico; } \\
\text { universalizando; } \\
\text { qualidade de vida; } \\
\text { saúde }\end{array}$ & $\begin{array}{l}\text { Água tratada; } \\
\text { coletar e tratar } \\
\text { esgotos; saúde; } \\
\text { conforto; qua- } \\
\text { lidade de vida; } \\
\text { desenvolvimen- } \\
\text { to sustentável }\end{array}$ & $\begin{array}{l}\text { Serviços de abaste- } \\
\text { cimento de água; } \\
\text { esgotamento sanitário; } \\
\text { qualidade de vida; } \\
\text { desenvolvimento socio- } \\
\text { econômico; rentabi- } \\
\text { lidade; satisfação de } \\
\text { clientes e acionistas } \\
\end{array}$ \\
\hline \multirow[t]{3}{*}{ Visão } & $\begin{array}{l}\text { Unidade } \\
\text { de Con- } \\
\text { texto }\end{array}$ & $\begin{array}{l}\text { Ser referência } \\
\text { estadual como au- } \\
\text { tarquia municipal } \\
\text { com excelência e } \\
\text { equidade na pres- } \\
\text { tação dos serviços } \\
\text { de saneamento }\end{array}$ & ND & $\begin{array}{l}\text { Ser modelo de } \\
\text { gestão em sanea- } \\
\text { mento, autossus- } \\
\text { tentável, integrada } \\
\text { e comprometida } \\
\text { com a sociedade, } \\
\text { meio ambiente, } \\
\text { oferecendo um ser- } \\
\text { viço diferenciado e } \\
\text { reconhecido pelos } \\
\text { clientes. }\end{array}$ & $\begin{array}{l}\text { A EPCM será, } \\
\text { nos próximos } \\
\text { anos, uma } \\
\text { instituição } \\
\text { competitiva, } \\
\text { empreendedo- } \\
\text { ra, inovadora, } \\
\text { de referencia } \\
\text { nacional no de- } \\
\text { senvolvimento } \\
\text { de pesquisas e } \\
\text { na aplicação de } \\
\text { novas tecnolo- } \\
\text { gias }\end{array}$ & ND \\
\hline & $\begin{array}{l}\text { Localiza- } \\
\text { ção no Site }\end{array}$ & $\begin{array}{l}\text { "Responsabilidade } \\
\text { e Qualidade” => } \\
\text { Perfil }\end{array}$ & ND & “Missão e Visão" & $\begin{array}{l}\text { “Companhia" } \\
=>\text { Visão de } \\
\text { Futuro }\end{array}$ & ND \\
\hline & $\begin{array}{l}\text { Unidade } \\
\text { de Regis- } \\
\text { tro }\end{array}$ & $\begin{array}{l}\text { Referência esta- } \\
\text { dual; excelência; } \\
\text { equidade }\end{array}$ & ND & $\begin{array}{l}\text { Modelo de gestão; } \\
\text { autossustentável; } \\
\text { integrada }\end{array}$ & $\begin{array}{l}\text { Competitiva; } \\
\text { empreendedo- } \\
\text { ra; inovadora; } \\
\text { referência } \\
\text { nacional; pes- } \\
\text { quisas e novas } \\
\text { tecnologias }\end{array}$ & ND \\
\hline
\end{tabular}

Onde: $N D=$ Não Disponível

Tabela 6 - Quadro síntese da análise de conteúdo temático-categorial, relativo à Missão e Visão das Prestadoras de Serviços de Saneamento.

para a EPCM, o objetivo é fazer da marca um sinônimo de categoria de produto, com aumento de participação de mercado ou de domínio de ação.

Com base na análise de frequência e na proporção de ocorrência das categorias analisadas (Tabela 5), constata-se que as autarquias municipais e a companhia estadual de saneamento (SAAE/01, SAAE/02 e CESB) focaram sua abordagem de informações nos usuários e na gestão ambiental e responsabilidade social. Por outro lado, as companhias com a participação de capital privado (EPCM e CPCA) focaram o conteúdo no desempenho institucional, em questões tais como: informações para 
os investidores, promoção institucional e gestão da qualidade dos serviços e produtos.

A análise de cumprimento do Decreto n5440/2005 (relativo à obrigatoriedade de divulgação de informações sobre a qualidade da água) mostrou, de maneira geral, que a abordagem e o acesso à informação não são adequados e acessíveis aos usuários. Ao contrário, as informações são repassadas de forma burocrática sem tratamento e elucidação, com pouca clareza na linguagem para alcançar o cidadão "comum".

Além disso, nem todas as prestadoras utilizam a home page na divulgação das informações e relatórios sobre a qualidade da água aos consumidores.

A análise da Missão e Visão Institucional (Tabela 6) leva à inferência acerca da percepção das prestadoras quanto ao conceito legal de saneamento. De acordo com Magalhães (2009), com o advento da Lei 11.445/07, foi estabelecida a conceituação atualizada de saneamento básico, sem ficar restrita ao abastecimento de água e esgotamento sanitário, mas incorporando os serviços de manejo de resíduos sólidos, e manejo das águas pluviais. A partir deste entendimento, os quatro componentes passaram a ser gerenciados de forma integrada. Com este novo conceito, é possível inferir que o SAAE/01 apresenta uma concepção limitada e desatualizada ao se autointitular ofertante de saneamento, quando, na verdade, este modelo de gestão atua apenas na prestação de serviços de abastecimento de água e esgotamento sanitário. Nesta mesma linha, a EPCM fundamenta sua ação no fornecimento de água, o que, de certa forma, não condiz com o amplo conceito preconizado na lei. Embora, em um primeiro momento, esta análise possa parecer superficial, cabe ressaltar que Missão e Visão Institucional fazem parte da Gestão Estratégica da Instituição, e refletem o seu entendimento e comprometimento em relação ao seu ramo de atuação e de seus colaboradores, fornecedores, investidores e usuários (SEIFFERT, 2008; DIAS, 2009).

Vale destacar, em consonância com a Lei $11.445 / 07$, que os serviços de saneamento são públicos e, portanto, possibilitam que diferentes agentes sejam responsáveis por etapas distintas da prestação, ressalvada a exigência de contrato de programa ou concessão pública entre os agentes, no caso de etapas interdependentes dos serviços.
Quando analisadas as principais palavras-chave da Missão e Visão Institucional, todas as prestadoras de serviço abordam o saneamento como promoção da saúde e da qualidade de vida. Nas demais palavras-chave (Tabela 6), claramente existem duas distinções de abordagem: viés entre as empresas públicas e as de participação de capital privado.

São nítidas as intencionalidades da atuação do agente público na provisão do saneamento como direito essencial da população, conforme observado na autarquia municipal (SAAE/01) "universalidade"; "excelência" e "equidade" - e na companhia estadual (CESB) - "universalização"; "autossustentável"; "integrada à sociedade"; "equilíbrio econômico". Por outro lado, as companhias estaduais de capital misto, mesmo quando têm o Estado como seu acionista majoritário, possuem comportamento similar ao de empresas privadas, que tratam os usuários dos serviços como "clientes", conforme verificado em EPCM - "competitiva"; "desenvolvimento de pesquisas" e "novas tecnologias" - e em CPCA - "rentabilidade"; "satisfação de clientes" e "acionistas".

Seguindo os preceitos da Lei 11.445/2007 (BRASIL; 2007), a prestação dos serviços públicos de saneamento básico deve estar assentada em princípios fundamentais, como a universalização do acesso; integralidade; equidade; de forma adequada à promoção da saúde pública e proteção do meio ambiente; adoção de métodos, técnicas e processos que considerem as peculiaridades locais e regionais; articulação com as políticas de relevante interesse social; eficiência e sustentabilidade econômica; utilização de tecnologias apropriadas; transparência das ações; controle social; segurança, qualidade e regularidade; e integração das infraestruturas e serviços com a gestão eficiente dos recursos hídricos.

Assim, a participação do poder público no fornecimento, financiamento e intervenções nas ações de saneamento, revela a questão de soberania e interesse institucional, pelo fato de abordar os serviços essenciais para a população e por constituírem monopólios naturais.

A participação de investimento privado é questionada por Hall e Lobina (2009), que a consideram pouco relevante no caso de países em desenvolvimento, pelo fato de não haver contribuição significativa no aumento da cobertura, no investimento em infraestrutura e nem melhoria na qualidade do serviço prestado pelo agente 


\begin{tabular}{|c|c|c|c|c|c|c|}
\hline \multirow{3}{*}{\multicolumn{2}{|c|}{ Critérios Avaliativos }} & \multicolumn{5}{|c|}{ Prestadoras de Serviço de Saneamento } \\
\hline & & \multicolumn{2}{|c|}{ Autarquias Municipais } & \multirow{2}{*}{$\begin{array}{c}\begin{array}{c}\text { Companhia } \\
\text { Estadual }\end{array} \\
\text { CESB }\end{array}$} & \multicolumn{2}{|c|}{$\begin{array}{l}\text { Empresa/Companhia Pública } \\
\text { (aberta ou mista) }\end{array}$} \\
\hline & & SAAE/01 & SAAE/02 & & EPCM & CPCA \\
\hline \multirow[t]{2}{*}{ Aspectos } & Positivos & $\begin{array}{l}\text { i) informa } \\
\text { o status do } \\
\text { abastecimento; } \\
\text { ii) apresenta re- } \\
\text { latórios de qua- } \\
\text { lidade da água; } \\
\text { iii) central de } \\
\text { atendimento } \\
\text { com a possibi- } \\
\text { lidade de envio } \\
\text { de mensagens e } \\
\text { telefone } 0800\end{array}$ & $\begin{array}{l}\text { i) apresenta dicas } \\
\text { para economizar } \\
\text { água e promover a } \\
\text { proteção ambiental } \\
\text { ii) possui central de } \\
\text { atendimento } 24 \mathrm{~h}\end{array}$ & $\begin{array}{l}\text { i) disponibiliza } \\
\text { contatos de toda a } \\
\text { administração da } \\
\text { companhia; } \\
\text { ii) sitio simples, } \\
\text { com informações } \\
\text { diretas; iii) Fale } \\
\text { conosco atua } \\
\text { como canal direto } \\
\text { com a Assessoria } \\
\text { de Comunicação e } \\
\text { Marketing }\end{array}$ & $\begin{array}{l}\text { i) divulga } \\
\text { informações } \\
\text { de programas } \\
\text { ambientais; ii) } \\
\text { apresenta bom } \\
\text { esquema de } \\
\text { comunicação } \\
\text { social; iii) link } \\
\text { Fale Conosco } \\
\text { disponibiliza ao } \\
\text { usuário protoco- } \\
\text { lo de acompa- } \\
\text { nhamento da } \\
\text { reivindicação; } \\
\text { iv) informa a es- } \\
\text { trutura tarifária }\end{array}$ & $\begin{array}{l}\text { i) apresenta links } \\
\text { que interagem e } \\
\text { divulgam outras } \\
\text { ações do governo; } \\
\text { ii) no menu divulga } \\
\text { informações im- } \\
\text { portantes: Reduza } \\
\text { sua conta; Aprenda } \\
\text { Conosco; Resumo } \\
\text { da Semana; Quali- } \\
\text { dade da água; Guia } \\
\text { do Usuário }\end{array}$ \\
\hline & $\begin{array}{l}\text { Negati- } \\
\text { vos }\end{array}$ & $\begin{array}{l}\text { i) alguns links } \\
\text { não abrem } \\
\text { (Educação Sócio } \\
\text { Ambiental); } \\
\text { ii) informações } \\
\text { superficiais (Di- } \\
\text { cas e Dúvidas) }\end{array}$ & $\begin{array}{l}\text { i) o link Perguntas } \\
\text { Frequentes não } \\
\text { possui informações; } \\
\text { ii) conteúdos desne- } \\
\text { cessários }\end{array}$ & $\begin{array}{l}\text { i) links importan- } \\
\text { tes (Organograma } \\
\text { e Conta de Agua) } \\
\text { não funcionam ou } \\
\text { estão em desen- } \\
\text { volvimento }\end{array}$ & $\begin{array}{l}\text { i) informações } \\
\text { e notícias mais } \\
\text { relacionadas } \\
\text { com a promoção } \\
\text { institucional; } \\
\text { ii) apresenta } \\
\text { informações } \\
\text { periféricas para } \\
\text { os investidores }\end{array}$ & $\begin{array}{l}\text { i) o link Informa- } \\
\text { ções ao cliente é } \\
\text { o último da lateral } \\
\text { direita do site o } \\
\text { que dificulta o } \\
\text { acesso; ii) informa- } \\
\text { ções relacionadas } \\
\text { à promoção e ao } \\
\text { desempenho da } \\
\text { companhia }\end{array}$ \\
\hline \multirow[t]{2}{*}{$\begin{array}{l}\text { Usabili- } \\
\text { dade }\end{array}$} & $\begin{array}{l}\text { Comen- } \\
\text { tários }\end{array}$ & $\begin{array}{l}\text { Bom planeja- } \\
\text { mento gráfico e } \\
\text { visual, mas com } \\
\text { pouca interati- } \\
\text { vidade }\end{array}$ & $\begin{array}{l}\text { Visual e elementos } \\
\text { gráficos apropria- } \\
\text { dos. Possui interati- } \\
\text { vidade (twitter) }\end{array}$ & $\begin{array}{l}\text { Página simples e } \\
\text { com baixa intera- } \\
\text { tividade }\end{array}$ & $\begin{array}{l}\text { Página bem } \\
\text { elaborada e com } \\
\text { convergência de } \\
\text { mídias (vídeos; } \\
\text { fotos; folhetos; } \\
\text { jornais) }\end{array}$ & $\begin{array}{l}\text { Sítio harmônico e } \\
\text { que apresenta uma } \\
\text { aparente facilidade } \\
\text { de navegabilidade }\end{array}$ \\
\hline & Conceito & $\mathrm{S}$ & $\mathrm{s}$ & I & B & $S$ \\
\hline \multirow[t]{2}{*}{$\begin{array}{l}\text { Navega- } \\
\text { bilidade }\end{array}$} & $\begin{array}{l}\text { Comen- } \\
\text { tários }\end{array}$ & $\begin{array}{l}\text { Apresenta o } \\
\text { mapa do site, } \\
\text { mas alguns links } \\
\text { não funcionam }\end{array}$ & $\begin{array}{l}\text { Página muito pesada } \\
\text { e informações são } \\
\text { apresentadas por } \\
\text { meio de longos } \\
\text { textos }\end{array}$ & $\begin{array}{l}\text { Não apresenta } \\
\text { o mapa do site, } \\
\text { além de links im- } \\
\text { portantes que não } \\
\text { funcionam }\end{array}$ & $\begin{array}{l}\text { Apresenta gran- } \\
\text { de quantidade } \\
\text { de informações } \\
\text { interessantes. } \\
\text { No entanto, não } \\
\text { traz o mapa } \\
\text { do site, o que } \\
\text { dificulta o aces- } \\
\text { so direto aos } \\
\text { conteúdos }\end{array}$ & $\begin{array}{l}\text { Links repetidos no } \\
\text { menu secundário. } \\
\text { Apresenta buscador } \\
\text { de acesso rápido e } \\
\text { o mapa do site }\end{array}$ \\
\hline & Conceito & $S$ & I & $P$ & $S$ & $P$ \\
\hline \multicolumn{2}{|c|}{ Pontuação total } & 4 pontos & 2 pontos & 1 ponto & 5 pontos & 3 pontos \\
\hline \multicolumn{2}{|l|}{ Ranking } & $2^{\circ}$ & $4^{\circ}$ & $5^{\circ}$ & $1^{\circ}$ & $3^{\circ}$ \\
\hline
\end{tabular}

Tabela 7 - Critérios avaliativos e ranking dos sítios eletrônicos analisados

privado. Ademais, a ausência de marco regulatório pode reforçar ainda mais as distorções na desigual provisão desses serviços entre regiões e entre extratos sociais (SAMPAIO e SAMPAIO; 2007)

Na Tabela 7, são apresentados os resultados referentes aos critérios avaliativos e ranking dos sítios eletrônicos analisados. Em relação aos principais aspectos positivos para os usuários, vale destacar que no caso das autarquias municipais, o SAAE/01 informa o status do abastecimento e possui um link direto e ativo com a Presidência da autarquia, enquanto o SAAE/02 possui uma central de atendimento $24 \mathrm{~h}$. 
Por sua vez, a companhia estadual (CESB) disponibiliza contatos de toda a administração da companhia, portanto possui um canal de comunicação mais direto e pessoal com os usuários dos serviços. Na análise das companhias de sociedade de economia mista, a EPCM no link Fale Conosco disponibiliza, para o usuário, um protocolo de acompanhamento da reivindicação; a CPCA apresenta links que interagem e divulgam outras ações do governo estadual na área de proteção ambiental.

Nos sítios analisados observou-se que, nas autarquias municipais e na companhia estadual, alguns links importantes não funcionam (Educação Socioambiental; Dicas e Dúvidas; Perguntas Frequentes; Organograma e Conta de Água). Assim, fica constatada a existência de falhas na comunicação, interação e acesso às informações aos usuários. Nos sítios eletrônicos das companhias estaduais de economia mista, as implicações negativas dizem respeito às informações e notícias que estão voltadas à promoção institucional, com baixa comunicação com os usuários.

Quanto à navegabilidade e usabilidade dos sítios, as prestadoras de serviço apresentam planejamento gráfico e visual simples, mas efetivo. No entanto, quando analisada a interatividade, apenas a CESB possui canal de informação vinculado à rede social Twitter, apenas a EPCM apresenta a convergência de mídias, disponibilizando aos usuários: vídeos, fotos, folhetos e jornais.

Conforme Ferrari (2008), a usabilidade e a navegabilidade dos sítios eletrônicos fazem parte de um conjunto de características que definem seu grau de interação com o usuário, e revela mostras de evolução, que envolvem a qualidade de um sistema fácil e agradável de ser usado, pois tolera erros dos internautas, já que ninguém é obrigado a saber de antemão o caminho para chegar à determinada informação. Ferramentas que facilitam a navegabilidade oferecem a visão panorâmica de todo o conteúdo - tabelas de conteúdo; índices e mapas de site - têm fundamental importância. Assim, se o sítio for bem construído, os usuários precisarão clicar menos para encontrar o que procuram.

A avaliação da navegabilidade dos sítios mostrou que nenhuma das prestadoras cumpriu, satisfatoriamente, este requisito, seja pela falta do mapa do site, links importantes inativos, duplicidade de conteúdo, ou falta de informações.

No período analisado, o sítio eletrônico do SAAE/02 apresentou esporádicos problemas de conectividade ("fora do ar e de carregamento pe- sado"). Em algumas de suas páginas, constatou-se, ainda, excesso de rolagem (muitas informações em uma única tela) na página inicial e páginas internas.

Ferrari (2008) destacou que, na determinação de boas práticas da usabilidade e navegabilidade devem ser observados três princípios básicos: i) a arquitetura da informação ideal passa pelo desenho de um sistema de navegação mínimo, com poucos 'cliques' no mouse, para mover o visitante de forma útil; ii) o conteúdo deve ser escrito de acordo com as necessidades específicas do público on-line (muito curto e explorando bastante o uso de itens e palavras-chave em destaque) e iii) deve-se ter em mente, ao escrever, que os internautas não se atêm detalhadamente a todos os pontos do conteúdo da home page ("eles passam uma visita de olhos por tudo").

A categorização segundo critérios avaliativos de usabilidade e navegabilidade (Tabela 7) facilitou a classificação dos sítios na seguinte ordem decrescente: EPCM; SAAE/01; CPCA; SAAE/02 e CESB. Vale lembrar, no entanto, que esta classificação remete exclusivamente à percepção dos autores durante o acesso aos sítios no período analisado. Entende-se que, com o estímulo ao importante debate sobre a adequabilidade e o acesso às informações pelos usuários dos serviços de saneamento, o dever de informar e a transparência sejam adotadas de forma a garantir a abrangência da comunicação institucional com os usuários. Como ressalta Lauretti (2003), a transparência faz parte dos quatro pilares de sustentação das melhores práticas de governança; os outros são: equidade, a prestação de contas e a sustentabilidade.

\section{Conclusões e considerações finais}

Foram verificadas as limitações ao acesso e à divulgação das informações prestadas voluntariamente pelos operadores dos serviços de abastecimento de água e esgotamento sanitário. Além disso, os sítios analisados possuem baixa usabilidade e navegabilidade, o que dificulta ainda mais sua apropriação pelos usuários.

Constatou-se que as companhias e a empresa (CESB, CPCA e EPCM) priorizam o conteúdo de informações de interesse de investidores, a promoção institucional e da gestão de qualidade dos serviços e produtos. Além disso, estas possuem um comportamento mais próximo de empresas privadas, tratando os usuários dos serviços como clientes.

Já as autarquias municipais (SAAE/1 e SAAE/2), por sua vez, abordam prioritariamente informações 
do interesse dos usuários e voltadas para a gestão ambiental e a responsabilidade social, o que pode representar uma maior assimilação por parte do agente público de que o saneamento é um direito essencial da população e um dever do Estado.

Quando analisado o cumprimento do Decreto 5440/2005, relativo à obrigatoriedade de divulgação de informações sobre a qualidade da água, verificou-se que, de uma maneira geral, a abordagem e o acesso à informação não aparecem de forma adequada e inteligível aos usuários, faltando clareza na linguagem. Evidenciam-se as apresentações burocráticas, para fins de cumprimento da legislação, mas não há realce às não conformidades e nenhuma indicação de ações que minimizem ou evitem danos à saúde e ao meio ambiente, como preconiza o documento legal. Esta é uma constatação preocupante, porque, tradicionalmente, pesquisas realizadas para fins de caracterização de cobertura dos serviços de saneamento ainda não traduzem, por meio de indicadores, a qualidade dos serviços prestados, dificultando o alcance efetivo da confiança dos usuários nos serviços.

Desta forma, levando-se em consideração a legislação nacional vigente, é possível inferir que, além da divulgação de informações sobre a qualidade da água por meio de correspondência individual ou da própria conta de água, é necessário haver a combinação de diversos veículos de informação para que, de fato, as informações sejam assimiladas pelos consumidores.

\section{Agradecimentos}

Os autores agradecem ao Conselho Nacional de Desenvolvimento Científico e Tecnológico (CNPq) pela concessão do auxílio - bolsa de estudo de doutorado: GD -, concedida ao primeiro autor; e ao Programa de Pós-Graduação em Saneamento, Meio Ambiente e Recursos Hídricos da Universidade Federal de Minas Gerais, por ter disponibilizado recursos para a tradução do texto.

\section{Referências}

BARDIN L. Análise de conteúdo. Lisboa: Edições 70, 279p, 2011

BRASIL. Decreto Presidencial $n^{\circ}$ 5.440/2005. Brasília: Diário Oficial [da] República Federativa do Brasil, Poder Executivo, Brasília, DF, Seção 1. p. 3. Disponível em: http://www.planalto.gov.br/ ccivil_03/_Ato2004-2006/2005/Decreto/D5440. htm. Acesso em: 01 fev. 2012.
BRASIL. Lei 11.445 , de 5 de janeiro de 2007. Estabelece diretrizes nacionais para o saneamento básico. Brasília: Diário Oficial [da] República Federativa do Brasil, Poder Executivo, Brasília, DF, 08 jan. de 2007. Seção 1. p. 3. Disponível em: https://www. planalto.gov.br/ccivil_03/_ato2007-2010/2007/ lei/11 1445.htm. Acesso em: 01 jun. 2011.

BRASIL. Comentários sobre o decreto presidencial $n^{\circ}$ 5.440/2005: subsídios para implementação. Ministérios da Saúde, Justiça, Cidades e Meio Ambiente. Versão Eletrônica. Disponível em: http:// www.cvs.saude.sp.gov.br/05dec5440_com.pdf. Acesso em: 08 mai. 2012.

CENTRO DE ESTUDOS SOBRE AS TECNOLOGIAS DA INFORMAÇÃO E DA COMUNICAÇÃO (CETIC). Proporção de indivíduos que usam a internet para busca de informações e serviços online. Disponível em: http://cetic.br/usuarios/tic/2007/rel-int-09. htm. Acesso em: 08 mai. 2012.

CHO, C.H.; KHANG, H.K. The state of internet-related research in communications, marketing, and advertising: 1994-2003. Journal of Advertising, v.35, n.3, p. 143-163, 2006.

DIAS, R. Gestão ambiental: responsabilidade social e sustentabilidade. Editora Atlas: São Paulo. 1ed: $4^{\mathrm{a}}$ reimpressão. 2009. 196p.

FERRARI, P. Jornalismo Digital. São Paulo: Contexto. 3ed. $1^{\text {a }}$ reimpressão, 2008, 120p.

FLICK, U. Uma introdução à pesquisa qualitativa. 3. ed. Porto Alegre: Bookman, 2009, 408p.

HALL, D.; LOBINA, E. 2009. Public policy options for financing sewerage systems. In: CASTRO, J. E. \& HELLER, L. (Edit). Water and Sanitation Service. Public policy and management. United Kingdom: Earthscan, pp. 104 - 121, 2009

HELLER, L.; CASTRO, J. E. Política pública de saneamento: apontamentos teórico-conceituais. Engenharia Sanitária e Ambiental, v. 13, n.3, p. 284-295, 2007.

HELLER, P. G. B. Modelos de prestação dos serviços de abastecimento de água e esgotamento sanitário: uma avaliação comparativa do desempenho no conjunto dos municípios brasileiros. 125f. Tese (Doutorado em Saneamento, Meio Ambiente e Recursos Hídricos) - Escola de Engenharia, Universidade Federal de Minas Gerais, Belo Horizonte, 2012.

INSTITUTO BRASILEIRO DE OPINIÃO E ESTATÍS- 
TICA (Ibope /NetRatings). Número de brasileiros com acesso a internet chega a 79,9 milhões. Disponível em: http://www.ibope.com.br/calandraWeb/ servlet/CalandraRedirect?temp $=6 \& p r o j=$ PortalIBO $\mathrm{PE} \& \mathrm{pub}=\mathrm{T} \& \mathrm{db}=$ caldb\&comp=pesquisa_leitura\&ni vel=null\&docid=9725B59EOCD6FC43832579DC 005A03D9. Acesso em: 08 mai. 2012.

INSTITUTO BRASILEIRO DE GEOGRAFIA E ESTATÍSTICA (IBGE). Pesquisa Nacional de Saneamento Básico - 2008. IBGE, Rio de Janeiro, RJ, 2000, 219p.

INSTITUTO DE PESQUISA ECONÔMICA APLICADA (IPEA). Objetivos de desenvolvimento do milênio: relatório nacional de acompanhamento. Brasília: IPEA, 2004, 96 p.

LUK, S.T.K.; CHAN, W.P.S.; LI, E.L.Y. The content of internet advertisements and its impact on awareness and selling performance. Journal of Marketing Management, v.18, p. 693-719, 2002.

MAGALHÃES, T. 2009. Manejo de resíduos sólidos: sustentabilidade e verdade orçamentária com participação popular. In: Brasil. Ministério das Cidades. Secretaria Nacional de Saneamento Ambiental. CORDEIRO, B. S. (Coord.). Prestação dos serviços públicos de saneamento básico. Brasília, pp. 520 - 530, 2009.

OLIVEIRA, D. C.. Análise de conteúdo temático-categorial: uma proposta de sistematização. Revista de Enfermagem. Universidade Estadual do Rio de Janeiro, out/dez: 16(4): 569 - 576, 2008.

OHIRA, M. L. B.; SCHENKEL; M. B. C.; SILVEIRA, C. Critérios para avaliação de conteúdo dos sites dos arquivos públicos estaduais do Brasil. In: II Simpósio Internacional Propriedade Intelectual, Informação e Ética. Anais Eletrônicos ... Florianópolis, 12 a 14 de novembro de 2003. 20p.

ORGANIZAÇÃO DAS NAÇÕES UNIDAS (ONU). 2012. O Direito Humano à Água e ao Saneamento: marcos. Programa da Década da Água da ONU: Água sobre Advocacia e Comunicação (UNW-DPAC). $4 \mathrm{p}$.

PEIXOTO, J. B. Aspectos Econômicos dos Serviços Públicos de Saneamento Básico. Cadernos Temáticos: Panorama Nacional de Saneamento Básico. 2010. 56p.

REZENDE, S. C. HELLER, L. O saneamento no Brasil (políticas e interfaces). Belo Horizonte, Editora UFMG, $2^{\text {a }}$ ed., 2008, 387p.
RUBINGER, S. D. Desvendando o conceito de saneamento no Brasil: uma análise da percepção da população e do discurso técnico contemporâneo. 197 f. Dissertação (Mestrado em Saneamento, Meio Ambiente e Recursos Hídricos) - Escola de Engenharia, Universidade Federal de Minas Gerais, Belo Horizonte, 2008.

SAMPAIO, B.; SAMPAIO, Y. Influências políticas na eficiência de empresas de saneamento brasileiras. Econ. Apl. [online]. vol.11, n.3, pp. 369386. 2007

SEIFFERT. M, E, B. Sistemas de gestão integrada: qualidade, meio ambiente e saúde e segurança ocupacional. Editora Atlas: São Paulo. 1ed: $4^{\mathrm{a}}$ reimpressão. 2009. 187p.

SHIMP, T. A. Propaganda e Promoção: Aspectos complementares da comunicação integrada de marketing. 7. ed. Porto Alegre: Bookman, 2009. 648p.

VILELLA; R. M. Conteúdo, Usabilidade e Funcionalidade: três dimensões para a avaliação de portais estaduais de Governo Eletrônico na Web. 2003. 263f. Dissertação (Mestrado em Ciência da Informação). - Escola de Ciência da Informação, Universidade Federal de Minas Gerais, Belo Horizonte.

SOBRE OS AUTORES

Hygor Aristides Victor Rossoni*

Engenheiro Ambiental e Mestre em Ciência Florestal pela Universidade Federal de Viçosa (UFV), doutorando do Programa de Pós-Graduação em Saneamento, Meio Ambiente e Recursos Hídricos (PPGSMARH) da Universidade Federal de Minas Gerais (UFMG). Professor do Instituto de Ciências Exatas e Tecnológicas do Campus Florestal da UFV.

Izabel Cristina Chiodi de Freitas

Engenheira Civil, Especialista em Saúde Pública pela FIOCRUZ, assessora projeto UFMG/Secretaria Estadual de Meio Ambiente e Desenvolvimento Sustentável (SEMAD) - Fundação Estatual de Meio Ambiente (FEAM).

Sonaly Cristina Rezende Borges de Lima

Engenheira Civil e Mestre em PPGSMARH pela UFMG.

Doutora em Demografia pelo Centro de Desenvolvimento e Planejamento Regional da UFMG (CEDEPLAR/UFMG). Professora Adjunta da Escola de Engenharia da UFMG.

Fernanda Fonseca Pessoa Rossoni

Jornalista e Mestre em Ciência Florestal pela UFV. Doutoranda do PPGSMARH da UFMG. Assessora de Comunicação do Campus Florestal da UFV.

*Endereço: PPGSMARH da UFMG: Salas 4618 e 4619, $4^{\circ}$ andar do Bloco 1. Escola de Engenharia, Campus Pampulha - Avenida Antonio Carlos 6627, CEP 31270-901 - Belo Horizonte - MG - Brasil - Tel/Fax: +55 (31) 3409-1882.

E-mail:rossoni@ufmg.brou rossoni@ufv.br 


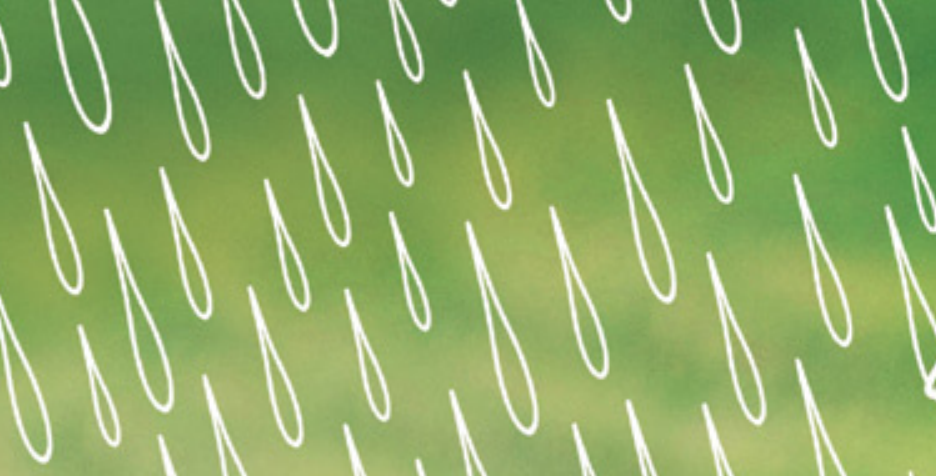

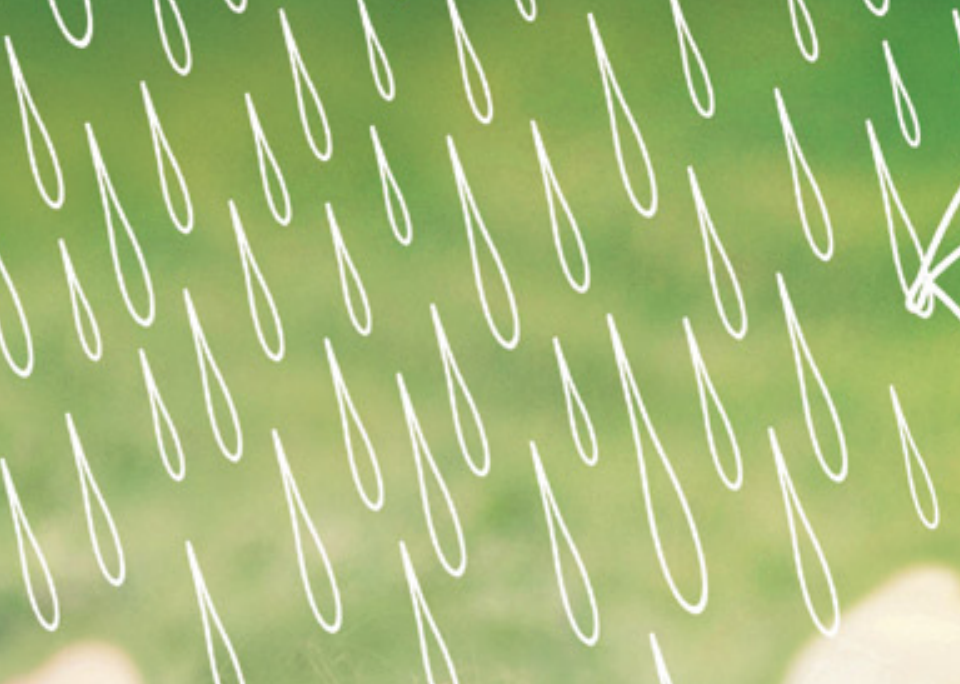<smiles>[c+]1c[c+]c1</smiles>

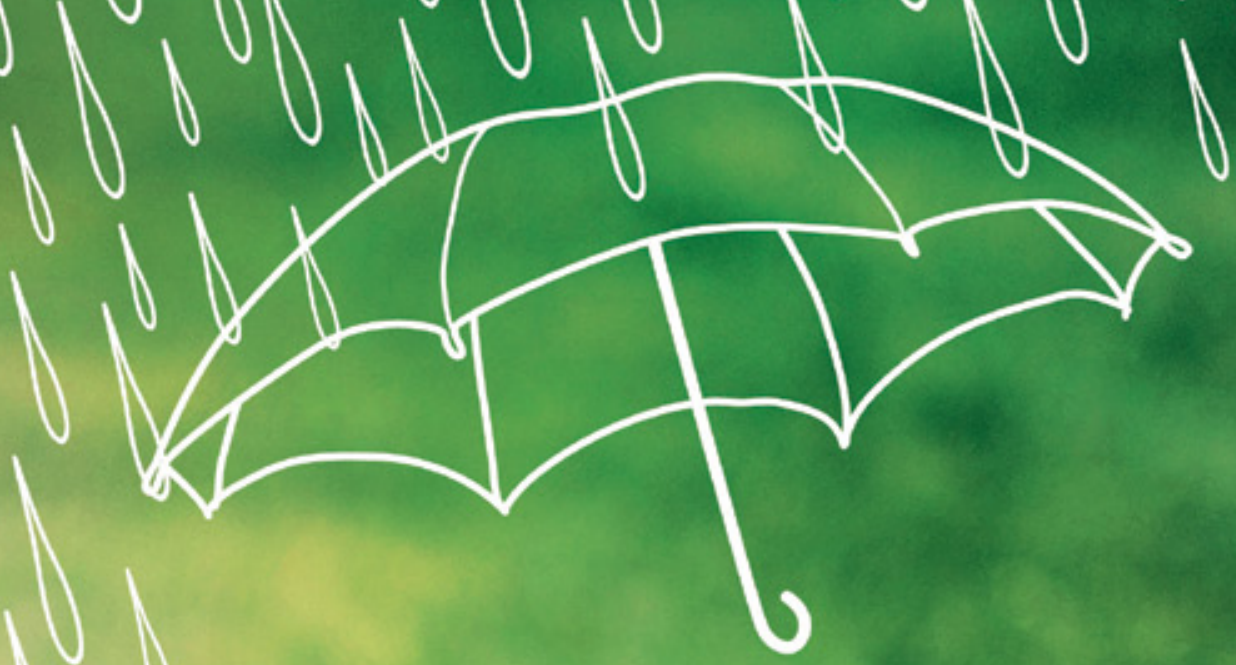

E você achando que $100 \%$ fosse o máximo que alguém pudesse se dedicar.

Sabesp $300 \%$ : $100 \%$ de água tratada, $100 \%$ de esgoto coletado e $100 \%$ de esgoto tratado.

O saneamento transforma a vida das pessoas. Por isso,

não medimos esforços para levar, até 2014 , o Sabesp $300 \%$
para todos os municípios do interior atendidos pela Sabesp.

- E, até 2018, para todas as outras cidades atendidas por nós.

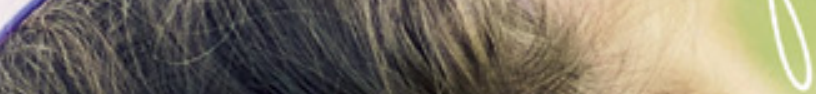

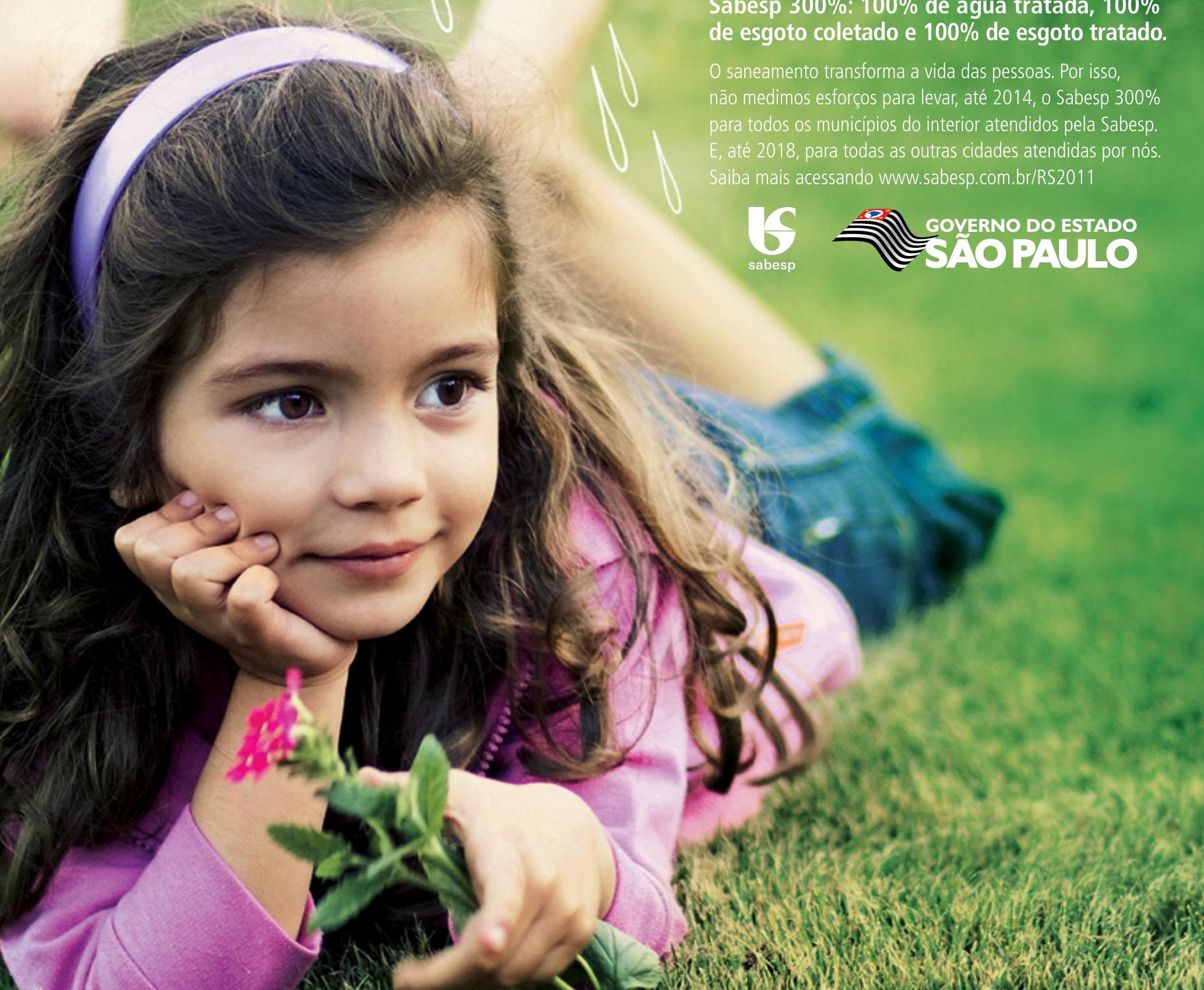

\section{6 气}
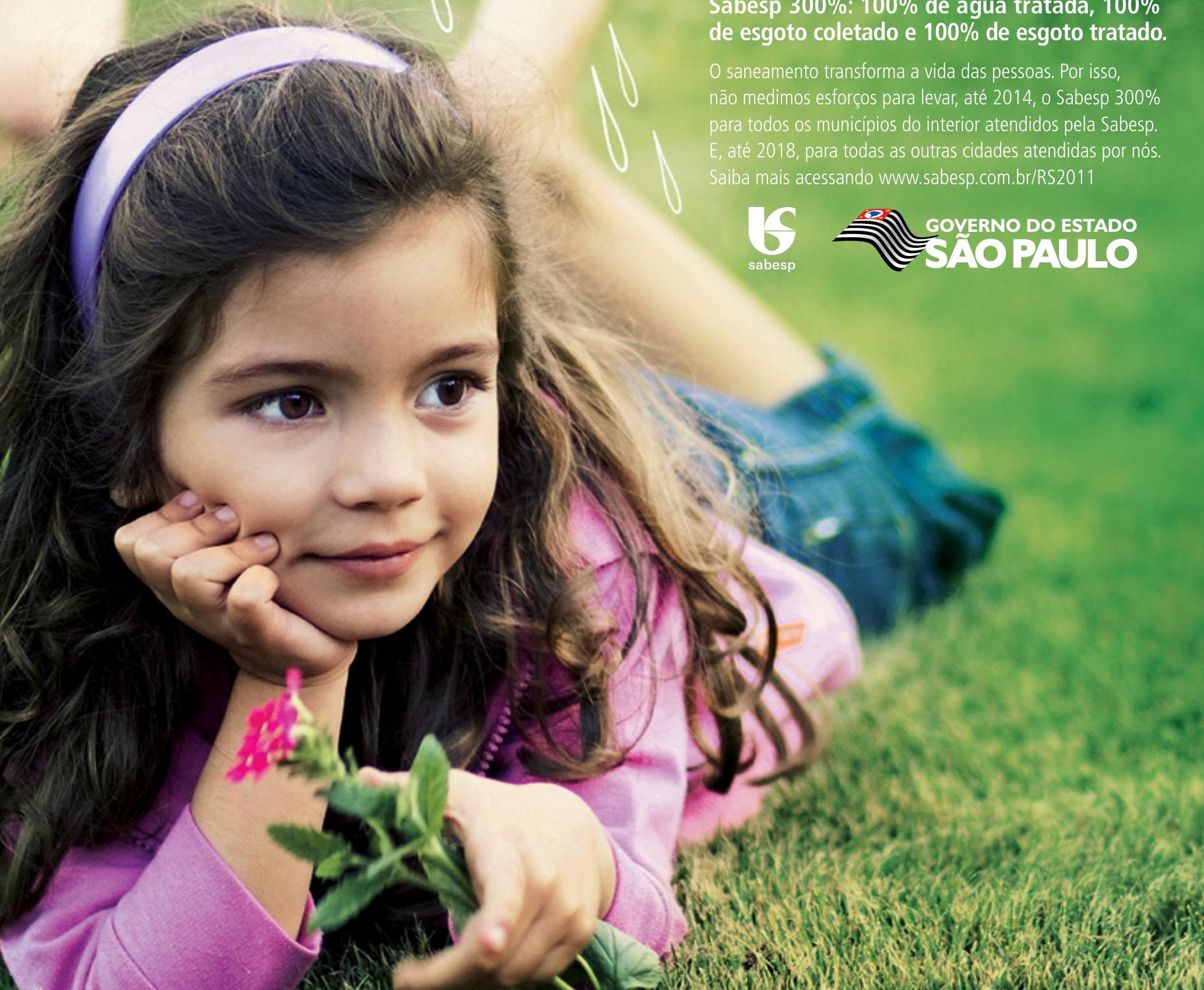

$\Delta M$
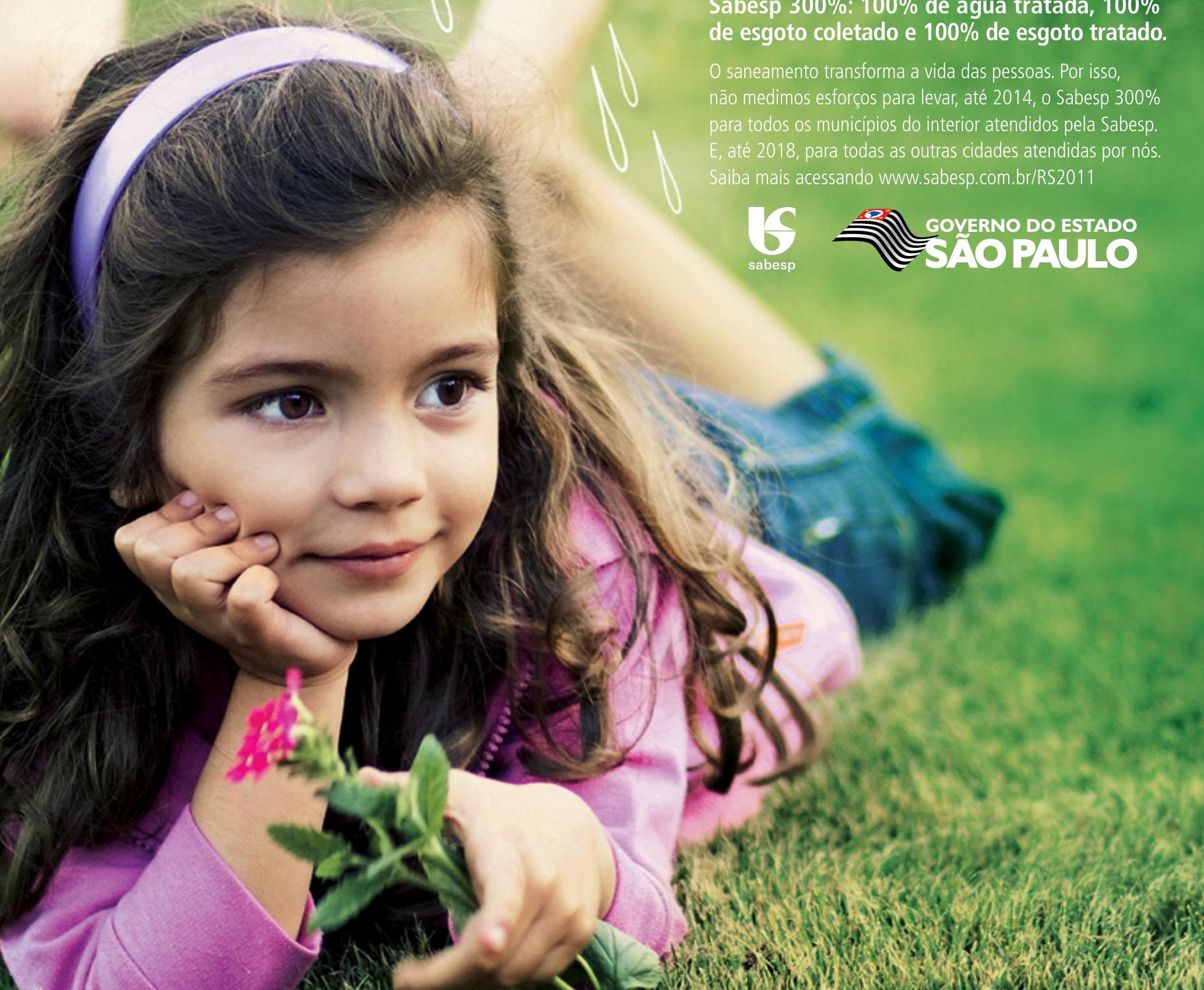